\title{
SELF-RESPONSIBILITY PREDICTS THE SUCCESSFUL OUTCOME OF CORONARY ARTERY BYPASS SURGERY
}

\begin{abstract}
Purpose: This study was designed to determine whether the acceptance of self-responsibility is an important determinant of the successful outcome of coronary artery bypass graft (CABG) surgery. The success of this costly intervention may be limited unless patients understand and adhere to the prescribed medical regimen, including diet and exercise after surgery. Patients suffering from chronic diseases must take charge of their own health and not abrogate that responsibility to the care providers.
\end{abstract}

Method: Questionnaires were designed to determine aspects of improved quality of life and self-responsibility. For the study, 73 patients who had undergone CABG surgery were selected from surgical patients in the private as well as the public sector. In order to assess the acceptance of self-responsibility, the spouses/care-givers of the patients were included in the study. Patients were interviewed during the first few days after the operation when they had returned to the wards and again six months and 12 months later. Successful outcome was measured in terms of improved quality of life using the criteria suggested by the Coronary Artery Surgery Study (Coronary Artery Surgical Study Principal Investigators, 1983). The acceptance of self-responsibility was then investigated as a possible factor influencing the improvement of the quality of life of these patients.

Results: The acceptance of self-responsibility was a significant factor predicting the successful outcome of CABG surgery in the group of patients who achieved an improved quality of life following surgery $(p<0.01)$. From the results of this study, a profile of South African patients with improved quality of life was identified. They are: Men, married, annual income > R50 000 (US \$8000), who had a normal sex-life prior to the operation.

They differ significantly from the group without an improved quality of life in the following aspects: they spend more hours participating in sport at school $(p=0.04)$, stop their sporting activities for a shorter period of time prior to the operation $(p<0.01)$ and are taller $(p<0.01)$. Twelve months after the operation their sexual performance has improved $(p<0.01)$ and they are not depressed $(p<0.01)$. Patients who accept self-responsibility for their recovery after $C A B G$ surgery have the following characteristics: married ( $p<0.01)$, have a level of education > grade $12(p=0.01)$, have an annual income $>R 50000(p=0.05)$. They differ from the group who did not accept personal responsibility in that they and their spouses/care-givers had a greater knowledge about the disease and the risk factor modification ( $p=0.01$; $p<0.01)$, and twelve months after the operation the patients are satisfied with the outcome of the operation $(p<0.01)$. Conclusions: A stepwise logistic regression established that the acceptance of self-responsibility was the strongest factor predicting an improved quality of life after CABG surgery. Patients who did not accept responsibility did not have an improved quality of life irrespective of the impact of all other parameters. Patients' satisfaction with the outcome of the operative procedure is an important predictor of the acceptance of self-responsibility. Realistic expectations of the outcome of CABG surgery will improve patients' satisfaction with the outcome. The knowledge of the spouse is a significant factor in the patients' acceptance of self-responsibility. Knowledge of the chronic nature of their disease as well as risk factor modification and realistic expectations of the outcome of CABG surgery influences patients' acceptance of self-responsibility.

KEY WORDS: SELF-RESPONSIBILITY, QUALITY OF LIFE, REHABILITATION, CORONARY ARTERY BYPASS SURGERY.

\section{CORRESPONDENCE TO:}

Professor CJ Eales,

Head: School of Therapeutic Sciences, Faculty of Health Sciences, Medical School, University of the Witwatersrand

7 York Road, Parktown 2193, Johannesburg, South Africa

Tel: +27 11717 2063/4, E-mail: ealescj@therapy.wits.ac.za 
$\mathrm{L}$ ife is a condition of human values and as far back as 1908, Royce made the statement that a human person is a life lived according to a human plan (Cohen, 1982). In order to have a plan it is essential to have life, as whatever we strive for, can only be achieved when living. If a person lives a life according to a plan then it seems logical that the patient will take responsibility for this plan. The aim of medical intervention should therefore be to maintain life. It is essential that not only should the prolongation of life be considered but so should the quality of that life. It was Socrates who said in an Athenian court that he feared some things more than death, and that it was not merely life itself, but the quality of life, that counts most (Cohen, 1982).

Mosteller argued that diseases were not always fatal but frequently became chronic and as a result affected the patient's comfort and happiness (Mosteller et al, 1980). This is particularly so in the case of patients who suffer from coronary artery disease. As a result of chronic disease patients are no longer able to lead their lives according to their original plan. The life-plan needs to be modified and refocused with the assistance of the medical team (rehabilitation team) but with the patient remaining the responsible member. The concept of a patient with chronic disease being responsible for leading a life of quality inspired this research. The philosophy being that the acceptance of selfresponsibility is an essential aspect of an improved quality of life. Improved quality of life being judged in terms of successful rehabilitation.

Since the introduction of surgical revascularisation for coronary heart disease, this operation has been and continues to be, a proven, effective therapy to relieve symptoms of angina, to improve the patient's quality of life and to prolong life (Connolly and Guyton, 1992). When other therapies are unsuccessful or contra-indicated, surgical intervention remains the end therapy for severe symptomatic coronary artery disease. Interventional cardiology and cardiac surgery have transformed the care of patients with ischaemic heart disease. In the USA the rate of coronary artery surgery increased by $102 \%$ between 1980 and 1992(Krumholz, 1997).

Comparing the USA sample with a similar Canadian sample, the patients in the USA had undergone bypass surgery 7.8 times as often as their Canadian counterparts. Interestingly though, when mortality rates were compared between the Canadian and USA sample of elderly patients undergoing bypass surgery, the one-year mortality rate was virtually identical indicating that it was not only the surgery that saved patients lives. Coronary artery bypass surgery is an expensive intervention and if it is not the sole way to save lives, should we not then consider other alternatives? At the start of the new millennium there is an international demand that medical care should become more cost effective and instead of increasing high tech facilities such low cost interventions as risk factor modifications, become essential. This is especially the case in South Africa where there is understandable pressure for equitable distribution of available health resources.

Research has suggested that aggressive risk factor modification can lower plasma lipid concentrations, reverse atherosclerosis and substantially diminish acute cardiac events in patients who already have the disease (DeBusk, 1996; Maines et al, 1997; Eagles and Gulati, 1996). Traditionally the role of the patient in the health care system has been characterised as essentially passive, demanding that patients place the responsibility for their health in the hands of health care professionals (Mahler and Kulik, 1990). There is however a growing feeling that patients should be more actively involved in their own care (Knowles, 1977; DeFriese et al, 1994; Oldridge, 1986).

In acute care the role of the physician is prominent and the patient plays a passive role. When it comes to risk factor modification the roles should be reversed. The patient needs the educational input and the motivation from the rehabilitation team but the patient is the only one who can actively comply and in this way bring about change. The operative success of coronary revascularization is limited unless the patient understands and adheres to the prescribed medical treatment, diet and exercise regime after surgery (Marshall, 1986). After the surgery the patient needs to take over from the physician and become the active role player.

Many patients regard the operation as a complete cure. They do not realise that they have a chronic disease and because of this belief, they do not comply with the required post-operative regime. They are convinced that they need take no further action in order to remain healthy (Kinchla and Weiss, 1985).

Patients report that the operation has improved them and that they are more active as a result. Regardless of the perceived improvement and activity, there is a tendency for the patients not to return to work. Where bypass surgery has been used as a method of treatment there is also a strong socioeconomic imperative that patients who have undergone such expensive surgery should become productive members of society again (Boll et al, 1987)

The ultimate goal of rehabilitation is the improvement of the quality of life of the patient (Livneh, 1988). It would therefore follow that the successful outcome of rehabilitation should be measured in terms of improved quality of life. Oldridge (1986) states that there are two important aspects when measuring successful rehabilitation of patients with coronary artery disease. These are an improved quality of life and an acceptance of self-responsibility for rehabilitation

The objectives of this study were to identify a cohort of cardiac patients who had undergone bypass surgery and who were considered to be successfully rehabilitated one year later. It could then be determined whether the acceptance of self-responsibility was a factor in their successful rehabilitation. Successful rehabilitation was assessed in terms of improved quality of life. We specifcally wished to determine whether the patient's acceptance of self-responsibility was a factor predicting successful rehabilitation.

\section{MATERIALS AND METHODS}

The Ethics Committee for Research on Human Subjects of the University of the Witwatersrand approved this research (Ethics clearance number: 36/9/92). 
The importance of the acceptance of self-responsibility as a factor in the successful rehabilitation of patients who have undergone coronary artery bypass surgery has not been determined.

For this research we had to determine what constitutes an improved quality of life. In addition, we needed to develop a scale to measure the degree to which a patient had accepted self-responsibility.

\section{THE ASSESSMENT OF IMPROVED QUALITY OF LIFE}

Quality of life is increasingly becoming an additional end point in the evaluation of the outcome of an intervention, in addition to the more traditional outcomes such as mortality and morbidity. There is no universal definition of improved quality of life but it is generally accepted that it can be defined by evaluating four domains: symptoms and side effects; physical function; social function and psychological status (Ory et al, 1994; Kinney et al, 1996) In this study improved quality of life was assessed by the method suggested by the Coronary Artery Surgery Study (CASS) Principal Investigators (CASS Principal Investigators and their Associates, 1983a). According to these researchers it was important to consider three criteria: improved functional status; amelioration of cardiac related symptoms and return to gainful employment and/or recreational activities after the intervention.

This method for determining improved quality of life after bypass surgery is generally accepted although it does not reflect the patient's perception of his/her quality of life. According to Testa and Simonson (1996) quality of life cannot be measured directly but can be measured indirectly by asking a series of questions. Subjective states are difficult to measure and thus investigators tend to bypass personal evaluations and rather infer quality of life through knowledge about individuals acquired from observation and measurement. The CASS method of establishing improved quality of life is an example of this procedure. Inferring subjective quality of life or well-being from external circumstances does not take fully into account the values, needs and adapt- ability of individuals to various life situations (Flanagan, 1982)

For this study, questions were added to the CASS questionnaire to elicit patients' subjective responses on issues around their quality of life as it was felt that measures that relied only on clinical judgement inadequately represented patient values. Questions considered to be important included satisfaction with the outcome, emotional health (depression and perceived stress) and sexual functioning (Ory et al, 1994)

\section{ASSESSMENT OF SELF-RESPONSIBILITY}

Self-responsibility means that the individual can be held morally accountable for his or her actions regarding the self. This can be in a physical sense, a psychological (attitudinal) sense or an educational sense (Oxford Dictionary, 1992). Self-responsibility in patients with chronic diseases implies that it is the moral duty of the patient to successfully execute the required health behaviour to maintain and improve their health.

There is no existing questionnaire to determine the acceptance of self-responsibility as defined above. An original questionnaire had to be designed to provide the required information (Eales and Stewart, 1994).

We considered that important measures of whether a patient had accepted responsibility, were the patient's and spouse's subjective evaluation of:

1. Whether the operation could be considered a cure.

2. Whether patients could manage their stress.

3. Whether patients had knowledge of the required diet, medication, exercise and effects of smoking.

4. Whether the spouse considered the patient fully responsible for his/her adherence to the prescribed diet; medication; exercise and abstinence from smoking.

Knowledge alone is not the most important indicator for self-responsibility. It is well known that persons such as cardiologists and physicians with excellent knowledge, sometimes smoke, eat what they like, do not exercise regularly and lead very stressful lives.
The combination of knowledge, intention and actual execution of the required behaviour is what is of great importance. In order to determine the behaviour of the patient it is important to include the opinions of the spouse/care-giver.

\section{SUBJECTS:}

Seventy three patients who had undergone coronary bypass surgery participated in the study together with their spouses or caregivers. The sample of patients was recruited on specific days over a specific period of time in order to minimise drop-outs from the sample selection.

\section{Inclusion Criteria}

For this study, surgeons from the private and public sector were approached for permission to include patients who had undergone bypass surgery. Patients who agreed were asked to sign a consent form. The selection of patients was regarded to be random as it was assumed that patients were admitted and operated on in a random manner. Only those patients who had undergone bypass surgery as the sole form of cardiac surgery, were included. All patients who could understand English and were willing to participate, were interviewed.

\section{Exclusion criteria}

Patients were excluded from the study if they were unable to communicate with the researcher; if additional surgical procedures had been performed; if they did not reside in South Africa; were unwilling to participate in the project; older than 80 years or could not be contacted telephonically after the operation.

\section{METHOD}

Questionnaires were administered to patients on three different occasions:

1. Post-operatively when the patient returned to the ward after having been in I.C.U. This contact was directly with the patient. The researcher assisted patients in completing the questionnaire

2. Six months after the operation. This contact was a telephonic interview.

3. One year after the operation. This contact was also a telephonic interview. 
Extracting the required information from patients' ward files, visiting cardiothoracic surgeons' and physicians' rooms and recording the relevant information from their files, completed the medical questionnaire.

According to Wenger et al (1984) a neglected area of research is comparing the spouse's or significant other's perception of the outcome of the operation with that of the patient. To this end the spouse was interviewed telephonically at six months and one year after the operation.

\section{RESULTS}

\section{Sociodemographic Data}

The baseline sociodemographic and clinical characteristics in the immediate post-operative period of 73 patients, are presented in Table 1. Sixty-one patients were operated on in private hospitals and 12 in a public hospital.

Table 1 shows that over a period of 12 months, fifteen patients were lost to follow up. All were males. Five had died. All ten females could be traced one year later. The majority of the 73 subjects participating in this study were in a low income bracket, were white South Africans with few Asians. None of the patients who were out of work at the time of the operation returned to employment. Twelve months after the operation an additional 24 patients were out of work.

\section{RISK FACTOR PROFILE}

The information on risk factors was self-reported by the patients as only limited medical information was available from the ward files and physicians' files. (Table II)

Slightly more than a quarter of the sample $(27 \%)$ knew their total serum cholesterol concentrations. Only 26\% knew their systolic and diastolic blood pressures, in spite of hypertension having been present for a mean period of 12 years $(S D \pm 9)$. The patients in this sample were heavy smokers. Only six patients in this group had never participated in any sport. The active patients (sport at school and/or after leaving school) had stopped sporting activities an average of 25 years before the opera-

Table 1: Sociodemographic Information.

\begin{tabular}{|c|c|}
\hline 1. No of Patients & $\begin{array}{ll}\text { Admission (M/F): } & 73(63: 10) \\
12 \text { M onths (M/F): } & 58(48: 10) \\
\text { Deaths (M/F): } & 5(5-0)\end{array}$ \\
\hline 2. Marital Status & $\begin{array}{l}\text { Married: } 75 \% \text {; Single: } 4 \% ; \text { Divorced: } 11 \% \text {; } \\
\text { W idowed: } 10 \%\end{array}$ \\
\hline 3. Children per family & Mean: 2.6 (range $0-9)$ \\
\hline $\begin{array}{l}\text { 4. Population } \\
\text { Distribution }\end{array}$ & W hite: $83 \%$; Black: $5 \% ;$ Asian: 11\%; Coloured: $1 \%$ \\
\hline 5. Home Language & $\begin{array}{l}\text { A frikaans: } 47 \% \text {; English: } 40 \% ; \text { A frican: } 5 \% \text {; } \\
\text { O ther: } 8 \%\end{array}$ \\
\hline $\begin{array}{l}\text { 6. Family Income } \\
\text { (annual income) }\end{array}$ & $\begin{array}{l}62 \%<\mathrm{R} 50000,00 ; 19 \% \text { between } \mathrm{R} 50000,00 \\
\text { and } \mathrm{R} 12000,00 \text { and } 19 \%>\mathrm{R} 120000,00\end{array}$ \\
\hline 7. Educational Level & $56 \%$ Grade 12 or higher \\
\hline 8. Employment Status & (FT and PT): Pre-op: 70\%; 12 M onths: $37 \%$ \\
\hline 9. Occupational Status & $\begin{array}{l}62 \% \text { : Middle white collar workers, Skilled } \\
\text { artisans, Manual foremen, Farmers } \\
22 \% \text { : Professionals or Managers }\end{array}$ \\
\hline $\begin{array}{l}\text { 10. Religion as important } \\
\text { aspect of life }\end{array}$ & $69 \%$ : regarded religion important \\
\hline
\end{tabular}

M/F: Male/ Female

FT/ PT: Full Time/ Part Time

Table 111: Medical and Surgical Information.

\section{MEDICAL INFORMATION}

a) Prior to Admission

$51 \%$ Angina

$56 \%$ Previous myocardial infarct

$33 \%$ PTCA

$7 \% \quad$ CABG

b) On Admission

Angina: $84 \%$ (62\% severe; very uncomfortable or most severe pain ever experienced)

Tiredness: $48 \%$ Very tired often or worst tiredness one could expect to have

Breathlessness: 63\%

Additional Problems: 38\% (Ca prostate; old CVA etc)

\begin{tabular}{l|ll}
$\begin{array}{l}\text { 2. SURGICAL } \\
\text { INFORMATION }\end{array}$ & LVEF & $:$ mean $51 \%$ \\
& Vessels bypassed & $:$ mean $2.8(1-5)$ \\
& Bypass time & $:$ mean 111 mins $(32-230)$ \\
& Aortic cross clamp time & $: 57$ mins $(14-117)$
\end{tabular}

No of patients: 73

PTCA: Percutaneous Transluminal Coronary Angioplasty

CABG : Coronary Artery Bypass Graft Surgery

CVA: Cerebral Vascular A ccident

LVEF: Left Ventricular Ejection Fraction

$M$ ins: $\quad$ minutes

tion. As the mean age of the cohort was 57 years, this indicated that they had continued with sporting activities to a mean age of 32 years. 
Table 11: Risk Factor Profile.

\begin{tabular}{|c|c|}
\hline 1. Hypercholesterolaemia & $\begin{array}{ll}47 \%: & \text { Reported elevated serum cholesterol } \\
& \text { concentration } \\
27 \%: & \text { Reported their total serum cholesterol } \\
\text { concentrations. } \\
\text { Mean } 6.3 \mathrm{mmol} / \mathrm{I}(5-11.2 \mathrm{mmol} / \mathrm{l})\end{array}$ \\
\hline 2. Hypertension & $\begin{array}{l}41 \%: \text { Reported Hypertension } \\
26 \% \text { : Knew values } \\
\text { Reported mean systolic } 143 \mathrm{mmHg} \\
(110-190 \mathrm{mmHg}) \\
\text { Reported mean diastolic } 91.3 \mathrm{mmHg} \\
(60-130 \mathrm{mmHg})\end{array}$ \\
\hline 3. Smoking & $\begin{array}{l}75 \% \text { smokers ( } 96 \% \text { smoked cigarettes) } \\
\text { Mean pack years } 40.4 \text { ( } 2-150) \\
12 \text { M onths post-op: } 15 \% \text { still smoking }\end{array}$ \\
\hline 4. Physical Activity & $\begin{array}{l}92 \%: \text { at some stage of life } \\
85 \%: \text { at school (rugby, soccer, cricket): } \\
\quad \text { mean: } 8 \text { hrs/ week } \\
68 \% \text { after school (rugby, soccer, tennis): } \\
\quad \text { mean: } 6 \text { hrs/ week } \\
\text { Years sporting activity stopped prior to operation: } \\
\text { mean } 25 \text { years } \\
5 \% \text { At time of operation (golf, walking, cycling) }\end{array}$ \\
\hline 5. Family History of CHD & $58 \%$ reported a death in the family due to $\mathrm{CHD}$ \\
\hline 6. Stress & $\begin{array}{l}71 \%: \text { work related issues } \\
45 \% \text { : constant stress }\end{array}$ \\
\hline 7. Diabetes Mellitus & 15\%: $1 \%$ IDDM ; $14 \%$ N IDDM \\
\hline 8. B.M.I. & $\begin{array}{l}\text { Reported mean: } 27.8 \mathrm{~kg} / \mathrm{m}^{2}\left(20-37 \mathrm{~kg} / \mathrm{m}^{2}\right) \\
\text { Weight gain since school leaving: mean } 14.4 \mathrm{~kg}\end{array}$ \\
\hline 9. Alcohol Intake & $\begin{array}{ll}\text { Alcohol Intake: } & 48 \% \text { regular intake } \\
\text { Mean: } & 23 \text { drinks per week }(2-70)\end{array}$ \\
\hline $\begin{array}{l}\text { No of patients: } \\
\text { IDDM: } \\
\text { N IDDM: }\end{array}$ & $\begin{array}{l}73 \\
\text { Insulin Dependent Diabetes M ellitus } \\
\text { N on-Insulin Dependent Diabetes M ellitus }\end{array}$ \\
\hline
\end{tabular}

Table 1V: On admission into the trial.

\begin{tabular}{|l|r|r|l|}
\hline & \multicolumn{3}{|c|}{ Chi-square } \\
\hline $\begin{array}{l}\text { Improved quality of life } \\
\text { (Categorical data) }\end{array}$ & df & \multicolumn{1}{|c|}{$\chi^{2}$-value } & p-value \\
\hline Male & 1 & 5.31 & 0.01 \\
\hline Married & 1 & 5.44 & 0.02 \\
\hline Income > R50 000 p/a & 1 & 4.74 & 0.03 \\
\hline N ormal sex-life & 1 & 5.10 & 0.04 \\
\hline
\end{tabular}

Group 1 Improved quality of life $(n=17)$

Group 2 N o improved quality of life $(n=39)$
Medical and Surgical Information (Table III)

Two patients operated on had cancer of the prostate and another two had had cerebrovascular accidents (stroke) some time before the operation.

\section{SELF REPORTED IMPROVED QUALITY OF LIFE ( $N=56)$}

Because few patients (9) had an improved quality of life six months after the operation a decision was taken to consider only the data one year after the surgery. One year after CABG 17 males were judged to have an improved quality of life (Group1) and 39 patients were judged not to have an improved quality of life (Group 2). All 10 females were in Group 2. All variables were analysed to determine whether any statistically significant differences existed between the groups. The variables on admission into the trial that were significantly different between the two groups are presented in Table 1V. The table is split into two sections with the categorical data in the first section and the continuous data in the second section. A p-value of 0.05 or less was regarded as significant.

\section{IMPROVED QUALITY OF LIFE}

On admission into the trial (Table IV) Patients who had an improved quality of life 12 months after CABG surgery were statistically different from the group whose quality of life had not improved in that on admission they were married males with an income greater than R50 000 p.a. They had also reported a normal sex-life prior to hospital admission.

Patients with an improved quality of life in comparison to patients whose lives had not improved seemed to be taller, had participated more in sporting activities at school as well as carrying on with sport for a longer period prior to surgery. The difference in weight between the two groups was not significant.

Table $\mathrm{V}$ provides information on patients whose quality of life was improved twelve months after surgery. The categorical and continuous data are separated. 
Table 1V: On admission into the trial (Continued).

\begin{tabular}{|c|c|c|c|c|}
\hline & & \multicolumn{3}{|c|}{ ANOVA } \\
\hline \multicolumn{2}{|c|}{$\begin{array}{l}\text { Group } 1 \text { Improved quality of life } \\
\text { (Continuous data) }\end{array}$} & Mean & F-value & $p$-value \\
\hline \multirow[t]{2}{*}{ Taller (cms) } & Grp 1 & 176.53 & \multirow[t]{2}{*}{6.68} & \multirow[t]{2}{*}{0.01} \\
\hline & Grp 2 & 168.36 & & \\
\hline \multirow[t]{2}{*}{ W eigh more $(\mathrm{kg})$} & Grp 1 & 86.71 & \multirow[t]{2}{*}{3.57} & \multirow[t]{2}{*}{0.06 (N S) } \\
\hline & Grp 2 & 78.77 & & \\
\hline \multirow{2}{*}{$\begin{array}{l}\text { More hours of sport at } \\
\text { school per week (hrs) }\end{array}$} & Grp 1 & 10.68 & \multirow[t]{2}{*}{4.64} & \multirow[t]{2}{*}{0.04} \\
\hline & Grp 2 & 7.06 & & \\
\hline \multirow[t]{2}{*}{$\begin{array}{l}\text { Years sporting activities } \\
\text { stopped prior to CABG }\end{array}$} & Grp 1 & 15.67 & \multirow[t]{2}{*}{10.14} & \multirow[t]{2}{*}{$<0.01$} \\
\hline & Grp 2 & 27.70 & & \\
\hline
\end{tabular}

Grp 1 (Group 1; improved quality of life, $n=17$ );

Grp 2 (Group 2; no improved quality of life, $n=39$ )

Table V: Twelve Months after CABG.

\begin{tabular}{|l|r|r|r|}
\hline & \multicolumn{3}{|c|}{ Chi-square } \\
\hline $\begin{array}{l}\text { Group } 1 \text { Improved quality of life } \\
\text { (Categorical data) }\end{array}$ & \multicolumn{1}{|c|}{ df } & \multicolumn{1}{|c|}{$\chi^{2}$-value } & \multicolumn{1}{l|}{-value } \\
\hline Returned to work & 1 & 11.39 & $<0.01$ \\
\hline No angina & 1 & 8.14 & $<0.01$ \\
\hline A ctivity levels > pre-operative levels & 1 & 43.06 & $<0.01$ \\
\hline A bsence of breathlessness & 1 & 6.90 & 0.01 \\
\hline $\begin{array}{l}\text { Knowledge that smoking had an effect } \\
\text { on CVS }\end{array}$ & 1 & 8.66 & $<0.01$ \\
\hline Sexual performance better than before & 1 & 9.87 & $<0.01$ \\
\hline Spouse knew diet patients had to follow & 1 & 4.33 & 0.04 \\
\hline Spouse considered operation a cure & 1 & 6.11 & 0.01 \\
\hline $\begin{array}{l}\text { Spouse considered patient's activity } \\
\text { levels > pre-operative level }\end{array}$ & 2 & 8.85 & 0.01 \\
\hline $\begin{array}{l}\text { Group 2 (no improved quality of life) } \\
\text { (Categorical data) }\end{array}$ & & & \\
\hline Symptoms post-operatively & 1 & 5.30 & 0.02 \\
\hline W ere depressed & 1 & 6.84 & 0.01 \\
\hline
\end{tabular}

\section{IMPROVED QUALITY OF LIFE}

Twelve Months after CABG (Table V)

Return to work, absence of angina and activity levels greater than pre-operative levels (indicating improved functional capacity) were used to determine if
N S: not statistically significant

Breathlessness was not used as an indicator of cardiac disease because many patients had chronic respiratory disease as a result of excessive smoking and patients also confused breathlessness with being unfit. It is important that the absence of breathlessness was significant in the group with improved quality of life providing external validity for the method used to determine improved quality of life. Spouses considered patients cured, more active and they knew the diet patients should follow. Patients who were symptomatic and depressed one year after the CABG surgery did not have an improved quality of life. Patients complained of symptoms such as painful sternums, problems with leg wounds from where the veins had been harvested and sleeplessness.

\section{SELF-RESPONSIBILITY AS A FACTOR IN IMPROVED QUALITY OF LIFE (N = 58)}

Having identified those patients who had an improved quality of life one year after surgery, a Chi-square test was performed to identify patients who had accepted responsibility for maintaining their health. Forty one patients had accepted self-responsibility for their own health of whom 35 were males and 6 were females. Seventeen patients (13 males and four females) were shown not to be responsible for their health. The acceptance of self-responsibility as a significant factor in the group of patients with improved quality of life was then examined. (Table VI)

Not one patient who did not accept responsibility for his health had an improved quality of life. However, patients who were self-responsible did not necessarily have an improved quality of life.

\section{RESULTS OF STEPWISE LOGISTIC REGRES- SION TO DETERMINE THE PROBABILITY FOR IMPROVED QUALITY OF LIFE}

For this analysis logistic regression was used to estimate the probability that an individual would have an improved quality of life if a number of variables were considered. therefore these parameters are expected to be significantly different between the group of patients with improved quality of life and the group with no improvement in their quality of life.
The identified predictor variables were the following

- Height of patient 
Table V1: Self-Responsibility In Patients With Improved Quality Of Life One Year After CABG.

Group 1: Self-responsible $(n=41)$

Group 2: Not self-responsible $(n=17)$

\begin{tabular}{|l|l|l|l|}
\hline \multicolumn{1}{|c|}{ Frequency } & Self-responsible & $\begin{array}{c}\text { Not } \\
\text { self-responsible }\end{array}$ & Total \\
\hline $\begin{array}{l}\text { Improved quality } \\
\text { of life }\end{array}$ & 17 & 0 & 17 \\
\hline $\begin{array}{l}\text { N o improved } \\
\text { quality of life23 }\end{array}$ & 15 & 39 & 56 \\
\hline Total & 41 & 15 & \\
\hline
\end{tabular}

$\chi^{2}=8.93 ; p=0.003$.

Table V11: Self-Responsibility -

On Admission into the trial.

\begin{tabular}{|l|r|r|l|}
\hline & \multicolumn{3}{|c|}{ Chi-square } \\
\hline $\begin{array}{l}\text { Patients had accepted self-responsibility if: } \\
\text { (Categorical data) }\end{array}$ & $\mathrm{df}$ & \multicolumn{1}{|c|}{$\chi^{2}$-value } & p-value \\
\hline Married & 1 & 7.739 & 0.005 \\
\hline Education > St 10 & 1 & 6.371 & 0.012 \\
\hline Diabetes M ellitus & 1 & 4.417 & 0.036 \\
\hline Income > 50 000,00 & 1 & 3.863 & 0.049 \\
\hline
\end{tabular}

\section{Table V111: Self-Responsibility -}

Twelve months after CABG.

\begin{tabular}{|l|c|c|c|}
\hline & \multicolumn{3}{|c|}{ Chi-square } \\
\hline $\begin{array}{l}\text { Patients accepted } \\
\text { self-responsibility if: } \\
\text { (Categorical data) }\end{array}$ & df & $\chi^{2}$-value & p-value \\
\hline Satisfied with out-come of operation & 1 & 4.526 & 0.003 \\
\hline Depressed & 1 & 4.462 & 0.035 \\
\hline Hospital admissions < & 1 & 4.566 & 0.033 \\
\hline & & & \\
\hline Spouses judged patient to be: & 1 & 6.105 & 0.013 \\
\hline Cured by the operation & 1 & 7.860 & 0.005 \\
\hline More active than before the operation & & & \\
\hline
\end{tabular}

- Knowledge that smoking affects the cardiovascular system

- Number of years sporting activities were stopped prior to CABG surgery

- Better quality sex-life after the operation

- Acceptance of self-responsibility

- Married sidered important for the South African sample. The variables were:

1. Better quality of sex-life (categorical - yes or no)

2. Height of the patient (continuous value)

3. Number of years since stopped with sporting activities (continuous value)

4. Had accepted self-responsibility (categorical value - yes or no)

Goodness of fit $\chi^{2}=20.30 p=0.98$

The strongest predictor of an improved quality of life was then determined by calculating the probability that a patient will have an improved quality of life. At a sensitivity of $92.3 \%$ and a specificity of $81.5 \%$ the cutpoint was determined at 0.24 . A case would be judged to have improved quality of life if the probability was greater than the cutpoint. It was found that if the patient is not responsible the outcome will not be an improved quality of life irrespective of all other parameters being positive. In the case where the patient is tall $(188 \mathrm{cms})$ still actively involved in sport, and has an improved sex-life but is not responsible the probability is calculated as 0.021 which is less than the cutpoint and therefore the patient's quality of life would not have improved.

In Table V11 the variables in the immediate post-operative phase, at six months and at 12 months were then tested for statistically significant differences between the patients who were responsible and those who were not. This was followed by a stepwise logistic regression to determine the predictive factors for acceptance of self-responsibility.

The significant differences between the patients in the two groups were that patients who had accepted self-responsibility were on admission into this study, married, educated, beyond grade 12 and had incomes greater than R50 000 p.a. All 11 diabetic patients were in the selfresponsible group. These patients had a history of chronic disease which was under control and the fact that they were all identified in the group who was responsible supports the method used to identify self-responsibility.

Because the above model contained so many predictor variables a specified model was fitted into the regression model, consisting of variables con-

\section{SELF-RESPONSIBILITY}

Twelve Months after CABG (Table VIII) 
The patients in the group who had accepted self-responsibility were satisfied with the outcome of the operation. Although the spouses of the patients who accepted self-responsibility thought they were cured by the operation, the patients did not and were depressed. The depression could be due to the fact that they realised that they had a chronic condition. These patients also had significantly fewer hospital admissions after their operations than the group who were not responsible.

As knowledge was regarded an important aspect of self-responsibility the knowledge scores of the patients (scored out of 35) and spouses (scored out of 20) in the groups responsible and not responsible were also examined.

\section{SELF-RESPONSIBILITY}

\section{(Table IX)}

The self-responsible group were significantly more knowledgeable than the group who did not accept responsibility for their own health. Spouses of patients who were not responsible for their health had the lowest knowledge scores (32\%).

Stepwise logistic regression was used to estimate the probability that an individual would be self-responsible if a number of characteristics (variables) were considered.

\section{The identified predictor variables were the following:}

- High knowledge score of the spouse

- Patient satisfied with the outcome of the operation.

- Education > grade 12

- Patient depressed at 12 months

- Patients were diabetics

- Patients were married

- Income > R50 000

Goodness of fit: $\chi^{2}=36.76 ; p=0.92$

A p-value of 1.0 is regarded as a perfect fit

Logistic regression will also fit specified models. A decision was taken to fit a specified model with the characteristics that could possibly be altered and found most frequently in the South African population. The predictor variables fitted in the model were:

- Patient satisfied with the outcome of the operation (categorical yes, no)

Table 1X: Self-Responsibility Know ledge Scores (Twelve Months after CABG).

\begin{tabular}{|l|l|l|}
\hline Patients & $\begin{array}{l}\text { Mean Score } \\
\text { (Total }=\mathbf{3 5})\end{array}$ & $\begin{array}{l}\text { Mann Whitney U test } \\
\text { (p-value) }\end{array}$ \\
\hline Group 1 (self-responsible) & $17.8(51 \%)$ & 0.02 \\
\hline G roup 2 (not responsible) & $14.5(41 \%)$ & \\
\hline Spouse of: & Mean Score (Total = 20) & \\
\hline G roup 1 (self-responsible) & $10.9(55 \%)$ & 0.003 \\
\hline Group 2 (not responsible) & $6.4(32 \%)$ & \\
\hline
\end{tabular}

- Knowledge score of spouse (continuous.....?/20)

- Education > Grade 12 (categorical yes, no)

Goodness of fit: $\chi^{2}=25.16: p=0.69$

A p-value of 1.0 is regarded as a perfect fit

\section{DISCUSSION}

Seventeen patients (30\%) were identified with improved quality of life and 39 (70\%) patients were judged not to have improved quality of life one year after their CABG surgery according to the CASS criteria. The sentiment expressed by Kos-Munson et al (1988) that a successfully repaired heart does not necessarily guarantee a successfully repaired life seems particularly fitting for this group of patients.

The most significant finding of this study was that self-responsibility was an important factor in patients who had an improved quality of life. Of the 17 patients with improved quality of life all had accepted self-responsibility. From the statistical analysis it was clearly evident that if patients did not accept responsibility for their own health they would not have an improved quality of life one year after CABG surgery $(p<0.01)$. The number of patients who were responsible (41) was greater than expected considering that only 17 patients had an improved quality of life. However, all the patients who were selfresponsible did not have an improved quality of life. Assuming responsibility for one's health does not guarantee a successful outcome. This finding has important consequences for the treat- ment of patients with coronary artery disease. CABG surgery is not always a life-saving measure but a treatment to improve patients' quality of life by removing symptoms and improving functional capacity. It therefore becomes essential to include the acceptance of responsibility for rehabilitation, as one of the objectives of treatment. If this is not the case it is unlikely that the patient will have an improved quality of life and thus the outcome will not be successful. It is therefore essential that patients who are not self-responsible be identified and targeted to ensure their acceptance of self-responsibility for rehabilitation.

The fact that all 17 patients were males correlates well with the results reported by Steine et al (1996) indicating male sex to be a significant predictor of enhanced well-being after coronary artery bypass surgery. Not one female was identified with an improved quality of life. Of the patients who were selfresponsible one year after the $\mathrm{CABG}$ surgery $85 \%$ (35) were males and only $15 \%$ (4) were females. The sample of patients who were not responsible for their health consisted of $69 \%$ (13) males and $31 \%$ (6) females. It was not expected that females would be less responsible for themselves than males, especially when it came to modification of risk factors and looking after their own health. Women are usually responsible in supporting their partners as is evident from the observation that 30 of the selfresponsible patients were married males and clearly the support of a marriage partner contributed to their being responsible. Spouses of self-responsible 
patients were more knowledgeable than the group who were not responsible, thought patients to be cured by the operation and judged the patients to be more active after the operation than before.

With stepwise logistic regression the probability was established that patients who were satisfied with the outcome of the operation and had an educational level greater than grade 12 and were likely to be self-responsible irrespective of the spouses knowledge. When considering self-responsibility in patients who have educational levels < grade 12 , their satisfaction with the outcome of the operation will determine whether they will accept responsibility for their own health. It is therefore important, especially in patients who have an educational level less than grade 12 , that they are informed and guided to have a realistic appraisal of the outcome of surgery. This may enhance their satisfaction with the outcome and in this way the acceptance of self-responsibility will be promoted. The best possible way to achieve this objective would be by encouraging their attendance at a cardiac rehabilitation programme.

Another important finding of this study was that there were no significant differences between the group with an improved quality of life and the group who did not have improved quality of life as far as any of the observed medical parameters were concerned. This implies that the severity of the disease as measured in terms of left ventricular ejection fraction, the number of vessels bypassed, bypass time and aortic cross clamp time, did not influence the outcome when measured in terms of improved quality of life one year after surgery.

\section{CONCLUSION}

The most significant finding of this research was that self-responsibility was established as a significant factor in determining the improved quality of life of patients 12 months after CABG surgery. Furthermore, it was established that the acceptance of self-responsibility was the strongest predictive factor for an improved quality of life after CABG surgery. Other factors that were strong predictors of improved quality of life were more recent participation in physical activities prior to $\mathrm{CABG}$ surgery, height and an improved sex-life after CABG surgery.

The strongest predictors of selfresponsibility were satisfaction with the surgical outcome of the surgery, educational level beyond grade 12, and a spouse with knowledge of the disease and therefore knowledge of risk factor modification.

Accordingly it can be concluded that unless a patient with chronic heart disease accepts responsibility for his rehabilitation after the surgical intervention, the outcome will not be successful regardless of the adequacy of the surgical procedure. Patients, who are educated and satisfied with the outcome because they have realistic expectations, will be self-responsible.

Satisfaction with the outcome can be influenced by knowledge of lifestyle modifications, which will in turn lead to a sense of control. There is evidence in the literature that a sense of control is associated with life satisfaction. Knowledge is a modifiable characteristic so that it may be possible to improve patients' satisfaction with the outcome, if their knowledge of the disease, the intervention and the expected outcome is increased.

In conclusion it can be said that a human life of quality is lived according to a human plan. When chronic illness occurs life can no longer be lived according to the original plan. The role of the health care worker is to assist and support the patient to live a life of quality again by taking control of an altered life plan. Unless individuals become active participants in their rehabilitation, realise that they have a chronic disease and take responsibility to modify their life style, they will not have an improved quality of life and therefore will fail to have a successful outcome following CABG surgery.

A Patient suffering from a serious chronic cardiac disease, in the following statement poignantly expressed these sentiments: "Through the little deaths of illness we learn and grow... Finally you discover that you are responsible for your own self alone..." (Pettitt, 1988).

\section{REFERENCES}

Boll A, Klatt L, Koch J, Langbehn A F, Segeberg B 1987 Psychosocial factors influencing return to work after coronary artery bypass surgery (CABS). International Journal of Rehabilitation Research 10: 145-154

CASS Principal Investigators and their Associates 1983a Coronary Artery surgery Study (CASS): a randomized trial of coronary artery bypass surgery. Quality of life in patients randomly assigned to treatment groups. Circulation 68: 951-96

Cohen C 1982 On the quality of life: some philosophical reflections. Circulation 66 (suppl III): 29-33.

Connolly M W, Guyton R A 1992 Surgical intervention in coronary heart disease. In: Wenger N K, Hellerstein H K, eds. Rehabilitation of the Coronary Patient (third edition). New York, Churchill Livingstone: 323

DeBusk R F 1996 Multifit: A new approach to risk factor modification. Cardiology Clinics 14: 143-157.

DeFriese G H, Konrad T R, Woomert A, Norburn J E K, Bernard S 1994 Self-care and quality of life in old age. In: Abeles R P, Gift H C, Ory M G, eds. Ageing and quality of life. Broadway, New York, Springer Publishing Company: 99-117

Eagles C J, Gulati R 1996 Martin U Nonpharmacological modification of cardiac risk factors: part 1. Journal of Clinical Pharmacology and Therapeutics 21: 289-295.

Eales C, Stewart A 1994 Factors which may predict successful rehabilitation of patients who have undergone coronary artery bypass surgery: A pilot study. South African Journal of Physiotherapy 49: 45-49

Flanagan J C 1982 Measurement of quality of life: current of the art. Archives of Physical and Medical Rehabilitation 63: 56-59

Kinchla J, Weiss T 1985 Psychologic and social outcomes following coronary artery bypass surgery. Journal of Cardiopulmonary Rehabilitation 5: 274-283

Kinney M R, Burfitt S N, Stullenbarger E, Rees B, DeBolt M R 1996 Quality of life in cardiac patient research: A meta-analysis. Nursing Research 45: 173-180 
Knowles J H 1977 Responsibility for health. Science 198: 4322 (editorial).

Kos-Munson BA, Alexander LD, Hinthorn PAC, Gallagher E L, Goetze C M 1988 Psychosocial predictors of optimal rehabilitation post-coronary artery bypass surgery. Scholarly Inquiry for Nursing Practice: An International Journal 2: 171-193

Krumholz H M 1997 Cardiac procedures, outcomes, and accountability. New England Journal of Medicine 336: 1522-1523

Livneh H: Rehabilitation goals 1988 Their hierarchical and multifaceted nature. Journal of Applied Rehabilitation Counselling 19: 12-18

Mahler H I M, Kulik J A 1990 Preferences for health care involvement, perceived control and surgical recovery: A prospective study. Social Science of Medicine 31: 743-751

Maines T Y, Lavie C J, Milani R V, Cassidy M M,
Gilliland Y E, Murgo J P 1997 Effects of cardiac rehabilitation and exercise programs on exercise capacity, coronary risk factors, behavior, and quality of life in patients with coronary artery disease. Southern Medical Journal 90: 43-49

Marshall J, Penckofer S, Llewellyn J 1986 Structured postoperative teaching and knowledge and compliance of patients who had coronary artery bypass surgery. Heart and Lung 15: 76-82

Mosteller F, Gilbert J P, McPeek B 1980 Reporting standards and research strategies for controlled trials: agenda for the editor. Controlled Clinical Trials 1: 1

Oldridge N B 1986 Cardiac rehabilitation, self-responsibility, and quality of life. Journal of Cardiopulmonary Rehabilitation 6: 153-156

Ory M G, Cox D M, Gift H C, Abeles R P 1994 Aging and quality of life: celebrating new research discoveries. In: Abeles $\mathrm{R} P$, Gift H C, Ory M G, eds. Ageing and Quality of Life. Broadway, New York, Springer Publishing Company: 4

Oxford Dictionary: 1992

Pettitt G A 1988 Changes of the Heart: the role of love and will in illness and wellness: part 3 . New Zealand Medical Journal 101: 573-574

Steine S, Laerum E, Eritsland J, Arnesen H 1996 Predictors of enhanced well-being after coronary artery bypass surgery. Journal of Internal Medicine 239: 69-73

Testa M A, Simonson D C 1996 Assessment of Quality-of-Life Outcomes. New England Journal of Medicine 334(13): 835-840

Wenger N K, Mattson M E, Furberg C D, Elinson J 1984 Assessment of quality of life in clinical trials of cardiovascular therapies. The American Journal of Cardiology 54: 908-913

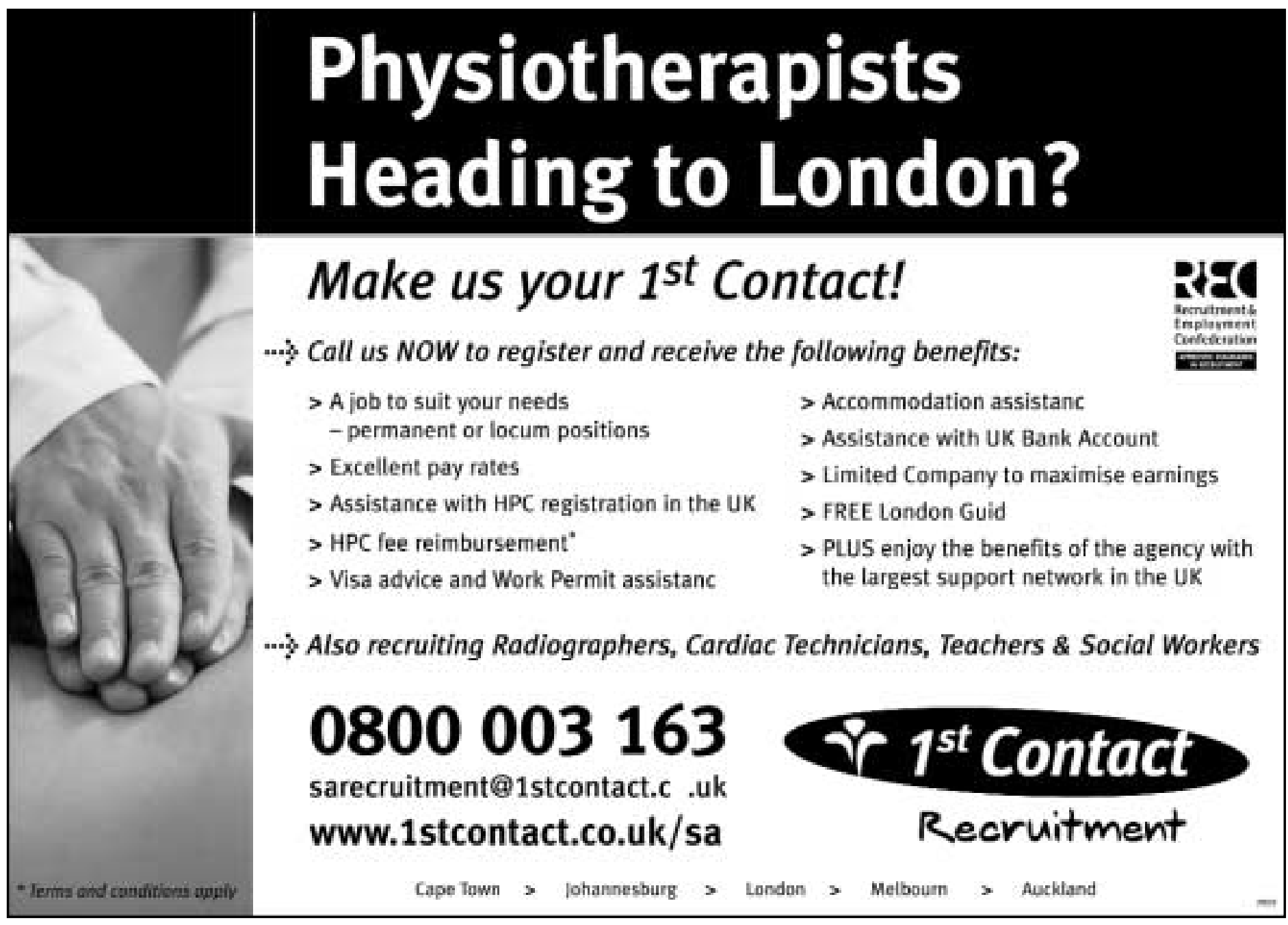

